\title{
Winter population structure and feeding of the chaetognath Eukrohnia hamata and the copepod Euchaeta antarctica in Gerlache Strait, Antarctic Peninsula
}

\author{
Vidar Øresland \\ Department of Zoology, Stockholm University, S-106 91 Stockholm, Sweden
}

\begin{abstract}
Eukrohnia hamata and Euchaeta antarctica are 2 dominant macrozooplankton predators in the Southern Ocean. Zooplankton samples were taken at 3 stations during July and August 1992, in waters west of the Antarctic Peninsula. E. hamata constituted up to $97 \%$ of all chaetognaths by number and up to $20 \%$ of net zooplankton by wet weight. E. hamata breeds at a low intensity and E. antarctica breeds at a high intensity during midwinter. Gut content analyses showed that Metridia gerlachei and the small copepods Oncaea spp. and Microcalanus pygmaeus were the main prey in both species. Estimated feeding rates between 0.3 and 0.5 copepods $\mathrm{d}^{-1}$ in E. hamata and the number of prey items found in the stomach of E. antarctica (Stages CV and CVI) indicated a feeding intensity during winter that was no less than earlier summer estimates. Rough estimates of daily predation impact showed that E. hamata could eat up to $0.2 \%$ of prey standing stock by number. It is suggested that the accumulative predation impact during winter by E. hamata and other carnivorous zooplankton may be large, especially since there was little evidence of prey reproduction that could counteract such a predation impact. About $1 \%$ of the E. hamata population was parasitized or decapitated by a small ectoparasitic polychaete. At 2 stations, 8 and $16 \%$ of all E. hamata were infected by a cercoid cestode larvae of the order Pseudophyllidea. E. hamata may therefore be an important transport host for cestodes that infect Antarctic vertebrates.
\end{abstract}

KEY WORDS: Zooplankton - Chaetognatha - Copepods - Euchaetidae - Predation · Feeding · Parasites Cestodes $\cdot$ Reproduction $\cdot$ Southern Ocean

\section{INTRODUCTION}

Polar waters have an extremely marked season of primary production that is limited to a few months during the short spring-summer period. The strong reduction of primary productivity and changes in the quality of available food during the remaining part of the year may represent a major constraint to the life history and production of many zooplankton species. Changes in feeding during the long polar winter range from complete cessation and dependence on stored energy to increased carnivory (see Hopkins et al. 1993, Huntley et al. 1994) that may affect the possibilities for growth, reproduction and survival during winter. Carnivorous zooplankton such as chaetognaths should be less directly coupled to the seasonality of primary production compared to herbivores and omnivores (see Clarke 1988).

Only limited information is available so far on the feeding of strictly carnivorous zooplankton during the Antarctic winter (Lancraft et al. 1991, Hopkins et al. 1993, Øresland \& Ward 1993). The possible effects on zooplankton population dynamics due to winter predation within the zooplankton communities are still unexplored. The Southern Ocean covers an enormous area that contains different water masses with plankton communities of different structure, origin and living conditions. A large geographical variation in primary production (including ice algae production), zooplankton feeding and reproduction, as well as in food web dynamics, should therefore be expected. 
The chaetognath Eukrohnia hamata and the copepod Euchaeta antarctica are dominant macrozooplankton carnivores in Antarctic waters. It was suggested by Oresland (1990) that a low but continuous predation impact on copepod populations by these species may have an important cumulative effect during the long winter period when little prey production takes place. Such a predation impact would be strengthened if other zooplankton species become carnivores during winter and if important prey species reduce their reproduction during winter. However, little is known about reproduction of copepods and the survival of their offspring during the Antarctic winter (see Franz 1988, Nöthig \& Gowing 1991). It may be reasonable to assume that predation impact on small copepods would be even greater if the predators themselves reproduce during winter since young predators (compared to older predators) generally prefer smaller prey items.

In this study the existence of midwinter breeding of Eukrohnia hamata and Euchaeta antarctica is inferred from the size and maturity stage distribution and the occurrence of egg sacs and spermatophores. Feeding in the winter in Gerlache Strait is compared with feeding in the summer, with some speculation concerning winter predation impact on copepods. The occurrence of parasites is reported since zooplankton, which play a central role in major Antarctic trophic pathways (Hopkins et al. 1993), are important parasitic intermediate hosts for parasites completing their life cycle in vertebrates.

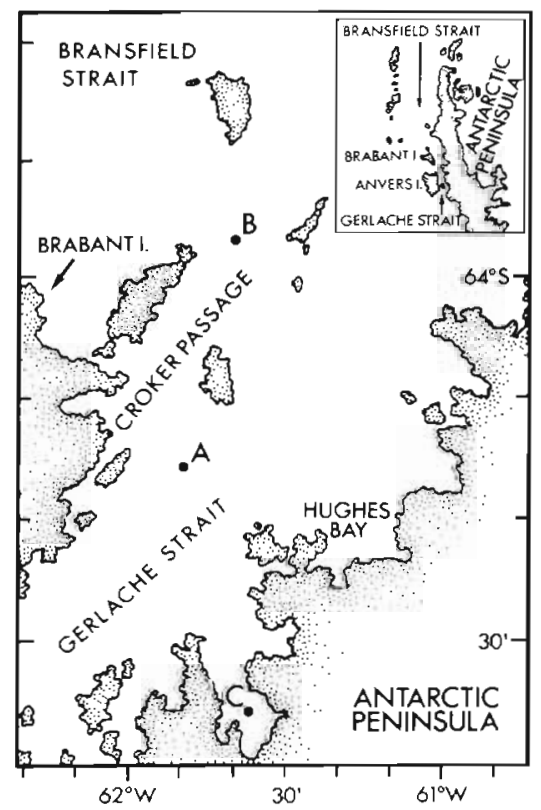

Fig. 1. Sampling area and Stns A, B and C in Gerlache Strait. Antarctic Peninsula

\section{METHODS}

Field sampling. Zooplankton samples were collected from RV 'Nathaniel B. Palmer' (USA) at 3 stations ( $A, B$ and $C$ ) in Gerlache Strait (Fig. 1) in July and August 1992. An area free of fast ice (a polynya) was found in the central part of Gerlache Strait, while the local bays and the northern and southern parts of Gerlache Strait were ice covered. Stns A and B were free of fast ice and Stn $C$ was ice covered. CTD casts were made at all stations, and all samples analysed in this study were taken from water of between 1 and $-1.8^{\circ} \mathrm{C}$.

Stn $\mathrm{A}$ was sampled in order to investigate the variation in length-frequency and maturity stage distribution by depth of the most abundant chaetognath, Eukrohnia hamata. The station $\left(64^{\circ} 16^{\prime} \mathrm{S}, 61^{\circ} 50^{\prime} \mathrm{W}\right)$ was sampled for $61 \mathrm{~min}$, between $12: 11$ and $13: 10 \mathrm{~h}$ on $23 \mathrm{July}$, using a MOCNESS net (multiple opening/closing net and environmental sensing system; $1 \mathrm{~m}^{2}$ opening, mesh size $330 \mu \mathrm{m}$ ). Samples were taken obliquely in six $100 \mathrm{~m}$ depth intervals from 900 to $300 \mathrm{~m}$ and in 1 additional interval from $300 \mathrm{~m}$ to the surface. Bottom depth varied from 1120 to $1132 \mathrm{~m}$ during the sampling. Sampling time per net varied from 3 to $25 \mathrm{~min}$. Ship speed was approximately 2 knots and mean wire speed was approximately 0.5 to $0.7 \mathrm{~m} \mathrm{~s}^{-1}$. The flow meter readings for the MOCNESS tows in this study were not reliable (due to malfunction).

Stn B (Croker Passage) is a deep area that was sampled in order to investigate the diet, and the lengthfrequency and maturity stage distribution of Eukrohnia hamata and the size of Euchaeta antarctica at Stages CV and CVI. The station ( $63^{\circ} 57^{\prime} \mathrm{S}, 61^{\circ} 40^{\prime} \mathrm{W}$ ) was sampled for $75 \mathrm{~min}$, between 15:34 and 16:49 h, on 11 August, using the MOCNESS net $11 \mathrm{~m}^{2}$ opening, mesh size $110 \mu \mathrm{m})$. The water column was sampled by a double oblique tow from the surface down to $35 \mathrm{~m}$ above bottom (at $1056 \mathrm{~m}$ ), and back to the surface. Ship speed and wire speeds were similar to those at Stn A.

Stn C (Charlotte Bay) is a relatively shallow area that was sampled for the same reasons as Stn B. This ice-covered station $\left(64^{\circ} 36^{\prime} \mathrm{S}, 61^{\circ} 37^{\prime} \mathrm{W}\right)$ was sampled 9 times between $22: 00$ and $21: 45$ h on 8 to 9 August using a $1 \mathrm{~m}$ diameter ring net with a mesh size of $130 \mu \mathrm{m}$. The samples were relatively evenly spaced over the $24 \mathrm{~h}$ period with 3 samples taken during daylight. The samples were taken vertically, from the bottom (at $365 \mathrm{~m}$ ) to the surface, at a speed of $0.5 \mathrm{~m} \mathrm{~s}^{-1}$. The average duration of these hauls was about $12 \mathrm{~min}$. All zooplankton samples were preserved in 5\% formaldehyde in sea water, buffered with borax, within 5 to 10 min after the samples were on the deck.

Laboratory methods. All chaetognaths and euchaetiids were sorted from the samples and appeared to be in good condition (the body, gut, antenna and most of 
the fins were intact). The length of all chaetognaths was measured (after 3 to $10 \mathrm{mo}$ in formaldehyde) in $1 \mathrm{~mm}$ size intervals under a stereomicroscope. Body length was measured from the anterior tip of the head to the end of the tail, excluding the tail fin. Maturity stages of Eukrohnia hamata were classified according to the development of the ovaries as follows: Stage 1, ovaries rudimentary or not visible; Stage 2, short and thin ovaries, ova hardly visible; Stage 3, ova easily visible, tail segment always full and opaque. The prosome length of all euchaetiids was measured to the nearest $0.1 \mathrm{~mm}$ under a stereomicroscope, using an eyepiece micrometer (calibrated to a stage micrometer). Occurrences of internal and external parasites that could be detected under the stereomicroscope were noted for both chaetognaths and euchaetiids. The length of external parasitic polychaetes found on chaetognaths was measured to the nearest $0.1 \mathrm{~mm}$. The microdissection technique and the analysis of predator gut content, which was inferred from identification of prey mandibles or other hard or special prey parts, followed the same procedure as in Øresland $(1987,1991)$.

All zooplankton $>1.5 \mathrm{~cm}$ (except chaetognaths) were removed from samples prior to the wet weight determination that followed the same procedure as in $\varnothing$ resland (1990), with the exception that all Euchaeta antarctica at Stages CV and CVI were also removed in this study. Percentage distribution of prey categories found in zooplankton samples was estimated from counting specimens from subsamples obtained using a Motoda box (Motoda 1959) and/or Kott's plankton splitter (Kott 1953). Six subsamples were taken from the Stn B sample and 1 subsample was taken from every second sample (5 subsamples in total) from Stn C. Subsequent counts from the last 3 subsamples did not change the accumulated percentage frequency for any prey category by more than a maximum of $5 \%$. Plots of standard error (SE) of subsample percentages for each of the copepod genera Metridia (CIII to CVI), Oncaea (CV and CVI), Oithona (CV and CVI), and Microcalanus (CV and CVI) against number of subsequent subsamples showed that the last subsample only contributed to a minor decrease in SE (see Bros \& Cowell 1987). Identifications of zooplankton were made mainly according to references given in Øresland (1990).

Daily feeding rates (FR) were estimated using:

$$
\mathrm{FR}=\frac{\text { Mean NPC }}{\text { Digestion time }(\mathrm{h})} \times 24
$$

where NPC is number of prey per carnivore. Estimates of digestion time for prey of Eukrohnia hamata are not yet available from Antarctic waters. Therefore, the digestion time data in Sagitta elegans at $6^{\circ} \mathrm{C}$ (Øresland 1987 ) were used both when estimating feeding rates of
E. hamata in this study, and in the summer study of Oresland (1990), to which the results will be compared. The digestion time used was $10 \mathrm{~h}$ for large copepods and $5 \mathrm{~h}$ for small copepods. The only other digestion time estimate at low temperature $\left(S\right.$. elegans at $0^{\circ} \mathrm{C}$ ) is $10.2 \mathrm{~h}$ for copepods (Feigenbaum 1982). The estimates in Øresland (1987) were chosen since they indicate an important difference between the digestion times of small and large copepods. The feeding rates presented in this paper can easily be recalculated when information on digestion time from Antarctic waters becomes available. There exist to my knowledge no good digestion time data for cold water predatory copepods of the size of Euchaeta antarctica and feeding rate estimates will therefore not be presented for this species.

\section{RESULTS}

Eukrohnia hamata was by far the most common chaetognath in this study. The relative abundances at Stns B and C, respectively, were: E. hamata, 89 and $97 \%$; Sagitta marri, 8 and $2 \%$; S. gazellae, 2 and $1 \%$. Few $S$. maxima were caught during this study. The mean percentage wet weight of E. hamata was $20 \%$ of that of the $130 \mu \mathrm{m}$ net zooplankton taken at Stn C. Standard deviation as a proportion of the mean (coefficient of variation) was $20 \%$, indicating that the estimate of the mean is representative of the population mean (Prepas 1984). Wet weight was not estimated at Stn B since only 1 sample was taken.

A greater proportion of small Eukrohnia hamata was found in the upper water layers at Stn A (Fig. 2). The proportion of large individuals increased by depth, from $0 \%$ in the 0 to $300 \mathrm{~m}$ interval to $15 \%$ in the deepest interval. The different depth strata were sampled for different time periods (between 3 and $25 \mathrm{~min}$ ). The number of individuals caught per minute provides a rough way of comparing differences in relative abundance between the different depth strata (n/min; Fig. 2). The maximum abundance of E. hamata was in the 300 to $400 \mathrm{~m}$ depth stratum, and the abundance was low below $700 \mathrm{~m}$ depth.

Eukrohnia hamata had a wide size distribution and most individual lengths were centred around the median at Stns B and C (Fig. 3). The higher proportion of small individuals at Stn B, compared to Stn C, may be due to a somewhat biased sampling towards the surface layer during the oblique tow at Stn B. Minimum lengths were 4 and $8 \mathrm{~mm}$, maximum lengths were 29 and $28 \mathrm{~mm}$, and the median lengths were 14 and $16 \mathrm{~mm}$, at Stns B and C, respectively. Size classes consisting of individuals making up less than $1 \%$ of the sample size are not shown in Figs. $2 \& 3$. Individuals at Stage 3 made up 2 and $1 \%$ of all individuals at Stns B 

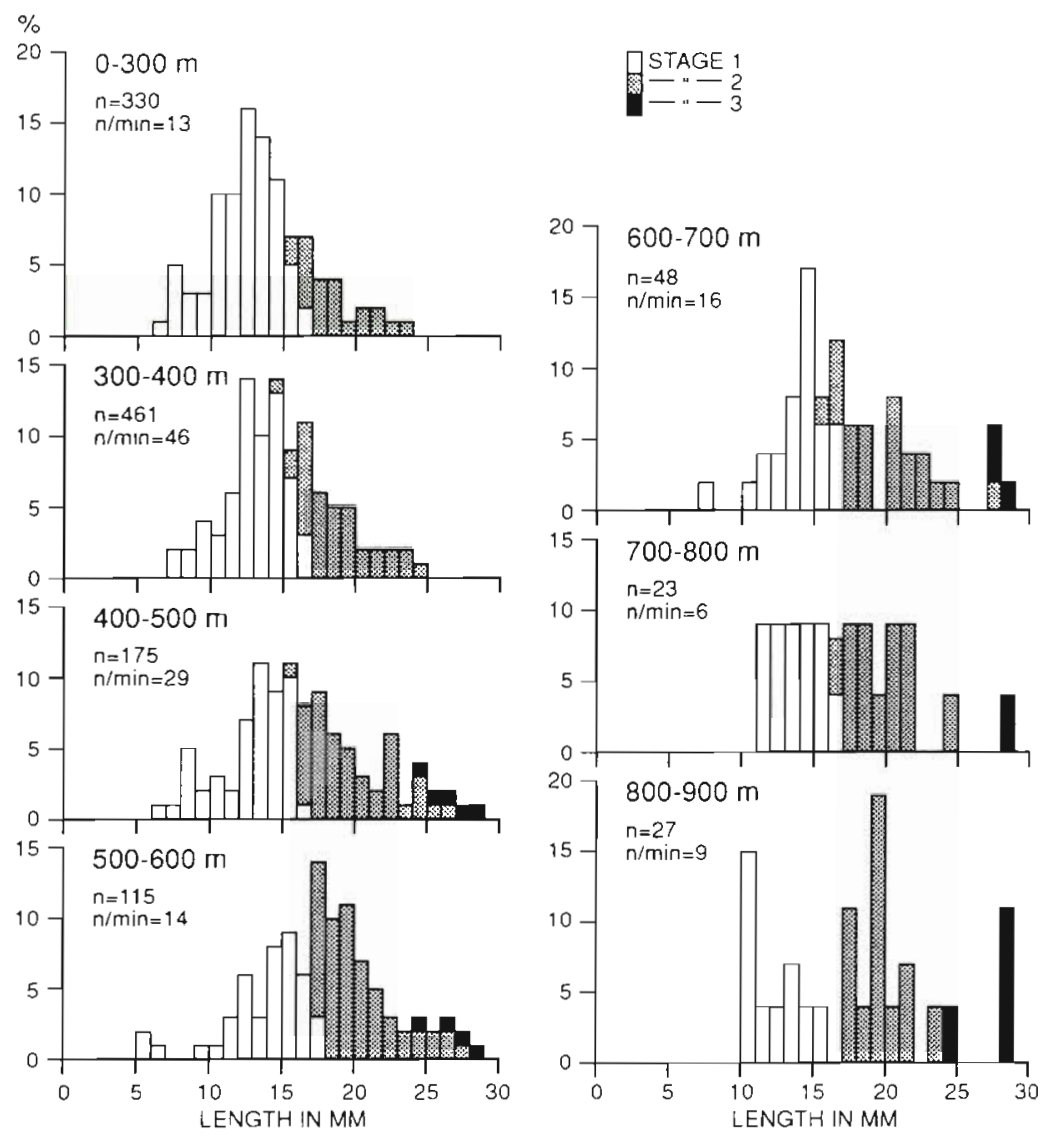

Fig. 2. Eukrohnia hamata. Length-frequency and maturity stage distribution within different depth intervals at Stn A. $\mathrm{n} / \mathrm{min}$ : estimate of relative abundance of $E$. hamata among depth intervals

and $C$, respectively. The few individuals at Stage 3 had large ova, their tails were full of sperm, and the seminal vesiculas were frequently found but no spermato-

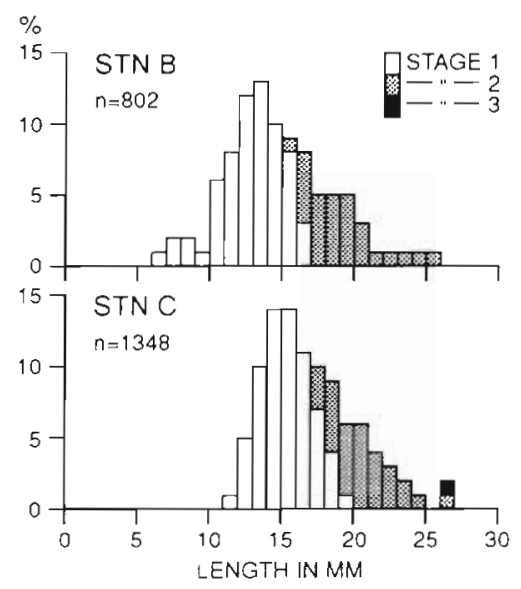

Fig. 3. Eukrohnia hamata. Length-frequency and maturity stage distribution throughout most of the water column in Croker Passage (Stn B, 0 to $1021 \mathrm{~m}$ ) and in Charlotte Bay (Stn C, O to $365 \mathrm{~m}$ ) during August 1992 phores ( $=$ sperm clusters) or brooding sacs (marsupium) were found (the same was true at Stn A).

Adult females of Euchaeta antarctica were much larger than adult males and specimens at Stage CV (Table 1). There was little or no difference between stations, when mean length of both sexes and stages are considered. Of the 132 adult females from Stn B, $25 \%$ had spermatophores and $89 \%$ had either welldeveloped ova, egg sacs, or both. Of the 62 adult males $43 \%$ had external spermatophores on leg 5. Adult males have reduced guts and mandibles and do not feed, and they are therefore not included in any of the following feeding data.

\section{Diet}

Table 2 shows that Metridia gerlachei and the small copepods Oncaea spp. and Microcalanus pygmaeus were the most common prey categories in the gut contents of both Eukrohnia hamata and Euchaeta antarctica. It is notable that, at both stations, the proportion of small copepods in E. antarctica is much higher at Stage CV than at Stage CVI. The proportion of copepods in the diet may be a conservative estimate since some of the unidentified prey may also have been copepods or other crustaceans but they could not be identified due to high degree of digestion and lack of mandibles. No evidence of cannibalism was found in any chaetognath or E. antarctica.

Table 1 Euchaeta antarctica. Prosome lengths (mm) of individuals from Stns B and C in August 1992. 95\%: confidence interval for mean length

\begin{tabular}{|lrrrrrr|}
\hline Stage & $\mathrm{n}$ & Mean & $95 \%$ & Min & Max & Range \\
\hline Stn B & & & & & & \\
Female VI & 132 & 6.35 & 0.09 & 5.5 & 7.5 & 2.0 \\
Female V & 22 & 5.17 & 0.14 & 4.5 & 5.7 & 1.2 \\
Male VI & 62 & 5.06 & 0.07 & 4.1 & 5.7 & 1.6 \\
Male V & 16 & 4.86 & 0.12 & 4.6 & 5.3 & 0.7 \\
& & & & & & \\
Stn C & & & & & & \\
Female VI & 14 & 6.20 & 0.22 & 5.7 & 6.9 & 1.2 \\
Female V & 54 & 4.97 & 0.05 & 4.7 & 5.5 & 0.8 \\
Male VI & 10 & 4.83 & 0.16 & 4.5 & 5.3 & 0.8 \\
Male V & 44 & 4.72 & 0.05 & 4.5 & 5.2 & 0.7 \\
\hline
\end{tabular}


Table 2. Percentage distribution of prey (by number) within the chaetognath Eukrohnia hamata and the copepod Euchaeta antarctica (Stages CV and CVI only), in Gerlache Strait, August 1992. NPC: number of prey per carnivore

\begin{tabular}{|c|c|c|c|c|c|c|c|c|}
\hline \multirow{3}{*}{$\begin{array}{l}\text { Prey } \\
\text { categories }\end{array}$} & \multirow{3}{*}{ E. hamata } & \multirow{2}{*}{\multicolumn{3}{|c|}{$\begin{array}{c}\text { - Stn B } \\
E \text {. antarctica }\end{array}$}} & \multirow{3}{*}{ E. hamata } & \multirow{2}{*}{\multicolumn{3}{|c|}{ - Stn $\mathrm{C}-\overline{\text { E. antarctica }}$}} \\
\hline & & & & & & & & \\
\hline & & Q VI & $q V$ & $0^{\prime} \mathrm{V}$ & & Q VI & o V & $O^{*} \mathrm{~V}$ \\
\hline Metrida gerlachei & 12 & 37 & 20 & 8 & 18 & 25 & 17 & 11 \\
\hline Oncaea spp. & 10 & 3 & 30 & 38 & 24 & 25 & 51 & 52 \\
\hline Microcalanus pygmaeus & 34 & 29 & 45 & 38 & 42 & 8 & 21 & 25 \\
\hline Oithona spp. & 1 & 0 & 0 & 0 & 1 & 0 & 2 & 4 \\
\hline Small unident copepods & 11 & 13 & 5 & 8 & 7 & 05 & 1 & \\
\hline Large unident copepods & 5 & 3 & 0 & 8 & 1 & 0 & 0 & 0 \\
\hline Unidentified & 27 & 16 & 0 & 0 & 7 & 42 & 5 & 7 \\
\hline \multicolumn{9}{|l|}{ Summary } \\
\hline Large copepods ${ }^{\star}$ & 17 & 40 & 20 & 16 & 19 & 26 & 17 & 11 \\
\hline Small copepods & 56 & 45 & 80 & 84 & 74 & 33 & 79 & 82 \\
\hline Unidentified & 27 & 16 & 0 & 0 & 7 & 42 & 5 & 7 \\
\hline No. of prey & 67 & 38 & 20 & 13 & 161 & 12 & 131 & 105 \\
\hline No. of predators & 802 & 132 & 22 & 16 & 1348 & 14 & 54 & 44 \\
\hline Mean NPC & 0.08 & 0.29 & 0.91 & 0.81 & 0.12 & 0.86 & 2.43 & 2.39 \\
\hline$\%$ empty predators & 92 & 74 & 27 & 31 & 87 & 29 & 75 & \\
\hline
\end{tabular}

The dominant prey categories Metridia gerlachei, Oncaea spp. and Microcalanus pygmaeus were also dominant in the water column at both stations (Fig. 4). Detailed comparison between proportions of prey categories in predators (Table 2 ) and in the water column (Fig. 4) should be avoided due to the limited data available. It is notable that Oncaea spp. made up as much as 41 and $57 \%$ (coefficient of variation of subsamples was 17 and $14 \%$ ) of all copepods at Stns B and C, respectively. Two species of Oncaea, of which one was identified as Oncaea antarctica, were breeding at Stn C since egg sacs were found on a few Oncaea spp. individuals. No Oncaea spp. egg sacs were found at $\operatorname{Stn} B$.

\section{Prey abundance in guts}

The NPC for Eukrohnia hamata, summarized in Table 2, was 0.08 and 0.12 at Stns B and C, respectively. All prey occurred as single prey in E. hamata except for a few cases of double prey occurrences (once at Stn B and 8 times at Stn C). The high percentage of empty $E$. hamata at both stations is notable. There were no indications of any diel feeding pattern at Stn C. The NPC for E. hamata varied between 0.07 and 0.16 and the percentage of empty individuals between 85 and $93 \%$ at Stn C. The few Sagitta marri found in this study contained Metridia gerlachei and small copepods, and the NPC was 0.12 and 0.24 for 76 and 34 individuals at Stns B and C, respectively. Among the $23 \mathrm{~S}$. gazellae found at these stations only 1 prey item, an $M$. gerlachei, was found.

Table 3 shows the feeding estimates of Eukrohnia hamata. The high proportion of small copepods in the water column is reflected in the NPC and the feeding rate estimates for small copepods. The feeding rate for large and small copepods together was 0.3 and 0.5 copepods $\mathrm{d}^{-1}$ at Stns $B$ and $C$, respectively. The estimates of feeding rate and predation impact on stand-

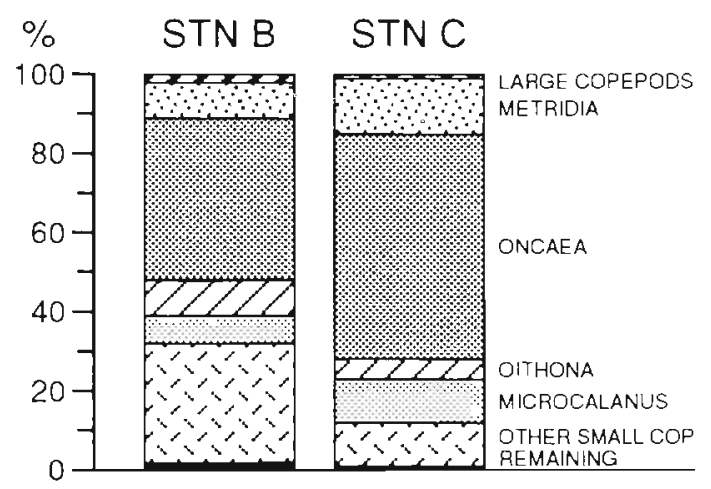

Fig. 4. Percentage distribution, by number, of prey categories throughout the water column at Stns B $(0$ to $1021 \mathrm{~m})$ and C $(0$ to $365 \mathrm{~m}$ ) based, respectively, on $110 \mu \mathrm{m}$ and $130 \mu \mathrm{m}$ mesh. net collections. Metridia gerlachei specimens were at Stages CIIl and CIV. Oncaea spp., Oithona spp. and Microcalanus pygmaeus specimens were at Stages CV and CVI 
Table 3. Eukrohnia hamata. Number of prey per carnivore (NPC), feeding rate as number of prey taken per day, and predation impact as daily proportion (\%) taken of prey standing crop in Gerlache Strait, August 1992. NPC, feeding rate [calculated as $(\mathrm{NPC} /$ digestion time) $\times 24$ ] and predation impact are estimated for a $24 \mathrm{~h}$ period. Digestion time is assumed to be $10 \mathrm{~h}$ for large copepods, and $5 \mathrm{~h}$ for small copepods and unidentified prey (see Øresland 1987, 1990). Standing crop is the estimated total number of individuals in all plankton hauls giving the relative proportion of E. hamata and large and small copepods

\begin{tabular}{|c|c|c|c|c|c|c|c|c|}
\hline \multirow{2}{*}{$\begin{array}{l}\text { Prey } \\
\text { category }\end{array}$} & \multicolumn{3}{|c|}{ NPC } & & \multicolumn{2}{|c|}{ Feeding rate } & \multicolumn{2}{|c|}{ Predation impact } \\
\hline & Stn B & & Stn $C$ & & Stn B & Stn C & Stn B & Stn C \\
\hline Large copepods & 0.01 & & 0.02 & & 0.03 & 0.05 & 0.14 & 0.15 \\
\hline Small copepods & 0.05 & & 0.09 & & 0.23 & 0.43 & 0.12 & 0.21 \\
\hline Unidentified & 0.02 & & 0.01 & & 0.11 & 0.04 & & \\
\hline All prey & 0.08 & & 0.12 & & 0.37 & 0.52 & & \\
\hline Standing crop & & Stn B & & Stn $C$ & & & & \\
\hline No. of E. hamata & & 802 & & 1348 & & & & \\
\hline No. of large copepods & & 18400 & & 47880 & & & & \\
\hline No. of small copepods & & 153600 & & 276480 & & & & \\
\hline
\end{tabular}

ing crop (see 'Discussion') should be interpreted with care due to few available data on chaetognath digestion times on different prey categories at low temperatures, and temporal and geographical variability in predator and prey occurrences.

Fig. 5 shows that multiple prey in Euchaeta antarctica was more common at Stn $C$ than at Stn B, and at

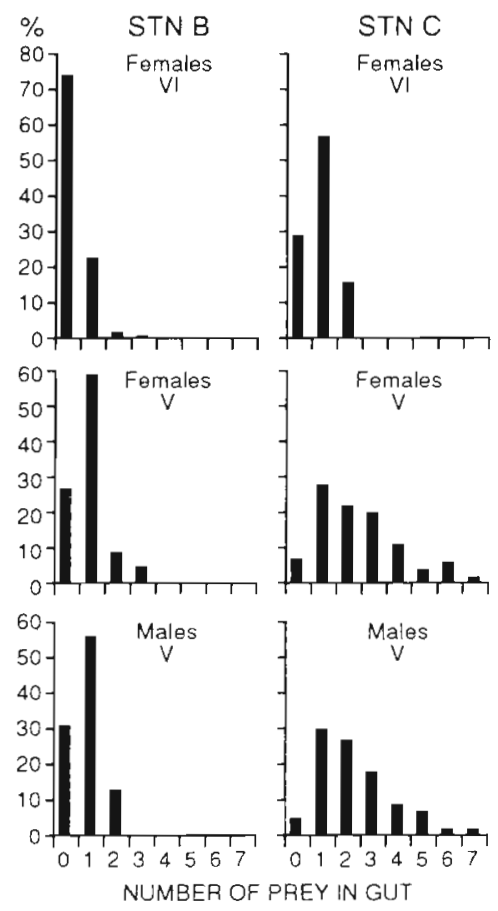

Fig. 5. Euchaeta antarctica. Percentage distribution of adult females (Stage CVI) and females and males at Stage CV, with different numbers of prey in the gut. Numbers of analysed predators and prey are given in Table 2
Stage CV than in adults. This is also clearly reflected in the NPC given in the summary in Table 2. The low number of $E$. antarctica Stages CV and CVI at Stn C did not warrant an analysis of diel feeding.

\section{Parasites}

The occurrence of a typhloscolecid polychaete on Eukrohnia hamata is given in Table 4. This polychaete is found attached behind the head of the chaetognath and as a result of the injuries the chaetognath eventually loses its head but continues to live for an unknown period of time (see Øresland \& Pleijel 1991). Between 0.5 and $1.6 \%$ of the chaetognaths were either parasitized or headless. Only single infections were found. The 25 polychaetes found at Stns A, B and C varied in length from 0.3 to $1.5 \mathrm{~mm}$ and the median and mean length was 0.40 and $0.56 \mathrm{~mm}$, respectively. One $3.9 \mathrm{~mm}$ long polychaete (largest polychaete found so far) was found on a Sagitta maxima taken at a station $\left(66^{\circ} 02^{\prime} \mathrm{S}, 65^{\circ} 56^{\prime} \mathrm{W}\right)$ in Crystal Sound, south of Gerlache Strait.

At Stns B and C, 8 and 16\% of all Eukrohnia hamata, respectively, were infected by a cercoid cestode larvae

Table 4. Eukrohnia hamata. Total number of chaetognaths analysed, percentage infected by polychaete and percentage which were headless

\begin{tabular}{|lrcc|}
\hline Stn & $\mathrm{n}$ & \% infected & \% headless \\
\hline $\mathrm{A}$ & 1179 & 1.0 & 0.2 \\
$\mathrm{~B}$ & 802 & 0.9 & 0.7 \\
$\mathrm{C}$ & 1348 & 0.4 & 0.1 \\
\hline
\end{tabular}


of an unidentified member of the order Pseudophyllidea (M. Køie pers. comm.). The cestodes were found in the body coelom, either free or attached to the outer gut wall. Infection by a single cestode was the rule, but a few cases of double infection, 6 and 23 at Stns $B$ and $C$, respectively, and 6 triple infections at $\mathrm{Stn} C$, were found. One cestode was also found in Sagitta marri at Stn B.

\section{DISCUSSION}

The relative occurrence of chaetognath species in this study was similar to that found during summer (December to March) in nearby Hughes Bay (Øresland 1990). Eukrohnia hamata made up, as a minimum, 89 and $93 \%$ of all chaetognaths, in this winter study and during summer, respectively. This demonstrates the dominance of $E$. hamata among the chaetognaths throughout the year in this area. In addition, the extremely high wet weight of E. hamata at Stn C $(20 \%$ of net zooplankton compared with a maximum of $7 \%$ during summer) suggests that its position in the plankton community may be even more important during winter in this area. However, knowledge of the geographical and vertical variability of the zooplankton composition is still basically lacking for the winter period in the Peninsula area.

Hagen (1985) observed no diel vertical migration in Eukrohnia hamata during summer (February) in the Peninsula area, and also found that the species occurred in greatest abundance between 200 and $750 \mathrm{~m}$ depth. He concluded that differences in size and stage distribution by depth were due to breeding migration of larger and more mature specimens into deeper waters. Although the data in Fig. 2 are limited, this study suggests, in agreement with the summer results of Hagen (1985), that there is a maximum abundance at an intermediate depth interval, as well as differences in size and stage distribution by depth, during the winter. This suggests that this vertical distribution may be rather constant throughout the year in this area. The reason(s) for this distribution, whether due to breeding or not, remains to be investigated. To my knowledge, winter studies in polar waters of the size and stage distribution by depth of this species are basically lacking.

The Eukrohnia hamata size and stage distributions at Stns B and C, and in the upper depth strata at Stn A, are strikingly similar to those found during the summer period (Oresland 1990). The absence of data showing seasonally different size and stage cohorts, the lack of good growth rate data, as well as the lack of knowledge of the number of broods that can be produced by a single adult generation, and the time required to pro- duce a single brood, makes it difficult to make interpretations regarding breeding periods and life span of E. hamata. However, the occurrence of a small proportion of Stage 3 and short Stage 1 individuals during both winter and summer indicate breeding throughout the year. Reproductive peaks may have been missed since data are still missing from the intermediate periods. The knowledge of possible brooding sacs in $E$. hamata is extremely limited and based on only a few observations (none in this study, nor in Øresland 1990) on individuals assumed to be E. hamata. Brooding sacs are either easily broken during sampling or extremely rare (see reviews by Alvarino 1990, Terazaki 1991).

The proportions of the smallest Eukrohnia hamata size classes increase by length during both the summer (Øresland 1990) and the winter. This may be due to temporal variability in reproduction, size-specific transport and/or escape through the net. Another factor may be allocation of energy to growth in length, rather than to body width and reproductive tissues, within the smaller size classes. Such a strategy may possibly reduce predation on the smallest size classes, and enable the young individuals to increase hunting success, and to take a quicker advantage of small copepods that are available throughout the year. To my knowledge, no successful experimental growth studies have so far been carried out on Eukrohnia hamata. This species seems to be extremely difficult to keep alive for more than a few days in aquariums (pers. obs.).

The life span of Eukrohnia hamata, interpreted from temporal size-frequency histograms, has been suggested to be $2 \mathrm{yr}$ in Arctic and Boreal waters (see review by Pearre 1991). If this holds true, it may be reasonable to assume a similar life span, or even longer, in Antarctic waters, due to the constant low water temperature. It has been argued that low temperatures reduce growth and development rate, leading to maturity at larger size, increased fecundity, and an increase in life span and maximum length. However, that temperature should be the only important factor in this respect has received criticism (see Pearre 1991). It is notable that the maximum size in this study $(29 \mathrm{~mm})$ is much shorter than that found in the warmer Korsfjorden, Norway (40 mm; Sands 1980). Therefore, genetic differences between populations, including differences in reproductive strategies and temporal feeding rates, as well as the temporal quality and size of food, should also be considered when interpreting and comparing growth and life history of different $E$. hamata populations. With that perspective, a population with a larger maximum size does not necessarily have to grow slower, reproduce later or have a longer life span than a population with a smaller maximum size 
The high occurrence of well-developed ova, egg sacs, and spermatophores in Euchaeta antarctica found in this study shows that intense breeding occurs during winter in Gerlache Strait. Evidence has been found for intense mating during summer, since $66 \%$ of the females from the northern Weddell Sea (January) and $71 \%$ of the females from the Gerlache Strait (March) (reported in Table 1 of Oresland 1991), had attached spermatophores. All adult males had spermatophores inside their bodies and/or on leg 5. Ferrari \& Dojiri (1987) found that the numbers of spermatophores per female with spermatophores appeared uniform through most of the year in the Southern Ocean Atlantic. One female taken in March (in Gerlache Strait) was carrying an egg sac (author's unpubl. data). The data available so far indicate that egg-sac development may start at a low level in late summer and continue until August, and probably even longer due to the high occurrence of spermatophores and ova found in August. The temporal distribution of breeding can be expected to vary geographically in the Southern Ocean. Ward \& Robins (1987) found that occurrence of spermatophores attached to females and egg sacs indicated probable peaks of reproduction in summer and winter in 2 fjord systems at South Georgia. The length of the life cycle of E. antarctica and the variability in vertical distribution and abundance of the different copepodite stages throughout the year remains unclear.

\section{Feeding}

Chaetognaths and Euchaeta antarctica are not likely to feed in the cod end. They never had any high incidence of undigested prey in the forward part of the gut but when occurring, such items were neglected. Voiding and defaecation of gut content in the net and during handling due to stress may perhaps occur but information on this is scarce (see Øresland 1987, 1991, 1993). The mean time the predators spent in the net is relatively short compared to the assumed digestion time. The number of prey recovered from individuals may be considered as a conservative estimate of their natural occurrence in the gut. The estimates of Eukrohnia hamata feeding rates on copepods in this winter study and during summer (Øresland 1990) overlap. The total feeding rate of copepods was 0.3 and 0.5 copepods $\mathrm{d}^{-1}$ in this study (at Stns $\mathrm{B}$ and $\mathrm{C}$, respectively), and 0.3 to 0.7 copepods $\mathrm{d}^{-1}$ during summer (December to March). Minor differences in feeding rate on small and large copepods between winter and summer, as well as between stations, should be interpreted with caution due to the limitations of the data. However, feeding rate data in Table 3 and in Øresland (1990) indicate a lower feeding rate on large copepods during winter and December, respectively. Also, it is notable that no large Euchaeta spp. or Calanoides acutus were found in the diet during winter and their proportion (by numbers) of all copepods in the water was low. E. hamata size-frequency distributions did not change seasonally and should therefore not affect seasonal diet and feeding rate

As in Eukrohnia hamata, no identified large copepods other than Metridia gerlachei were found in the diet of Euchaeta antarctica during winter. The proportion of small copepods in the diet approximately doubled from summer (Øresland 1991) to about $80 \%$ during winter in individuals at Stage CV. A similar seasonal increase in small copepods (mainly small Drepanopus forcipatus) was found in the diet of individuals at Stage CV around South Georgia (Øresland $\&$ Ward 1993). These gut content data strongly contradict that $E$. antarctica should cease feeding during winter, as suggested by Yen (1991).

The higher occurrence of multiple prey in Euchaeta antarctica at Stage CV compared with adults seems to be a general phenomenon since this was found also during summer and winter around South Georgia (Øresland \& Ward 1993) and during summer in Gerlache Strait (Øresland 1991). The diet and multiple prey data for males and females do not indicate any major differences in feeding at Stage CV due to sex. However, a. large geographical variability in feeding between Stns B and C, for both adults and individuals at Stage $C V$, is indicated by the multiple prey data, the NPC, and the percentage of empty predators.

\section{Predation impact}

A rough calculation of predation impact of Eukrohnia hamata during summer (Øresland 1990) showed that the daily predation on large copepods ranged from 0.03 to $0.06 \%$ and on small copepods it ranged from 0.10 to $0.58 \%$ of respective standing crop (by number). The corresponding estimates in this winter study (Table 3 ) at Stns $B$ and $C$, respectively, were $0.14 \%$ and $0.15 \%$ for large copepods and $0.12 \%$ and $0.21 \%$ for small copepods. Although the estimated predation impact per day is low it would strongly reduce the abundance of both large and small copepods during the long Antarctic winter if not counteracted by other factors

One factor affecting predation impact on prey populations is the temporal and geographical variability in predation impact. The daily predation impact does not need to be 'steady and constant' throughout the winter period to have an accumulative impact. However, better estimates based on temporally and geographically spaced data throughout the winter period are needed. 
The approximately 2 times lower estimate for Stn B compared to $\mathrm{Stn} C$ indicates that high variability is to be expected. This difference between stations may be due to differences in feeding rate and relative abundance of predator and prey, and perhaps to differences in towing time (Table 3 ). The $110 \mu \mathrm{m}$ and $130 \mu \mathrm{m}$ nets used at Stns B and C, respectively, may have underestimated the cyclopoid copepods, especially Oithona spp. (see Hopkins et al. 1993). However, the Oncaea spp. (CV and CVI) appeared in high proportions, while Oithona spp. (CV and CVI) were almost absent, in both the net samples as well as in the predator guts.

Another factor is the temporal and geographical variability in turnover rates of prey in relation to their predators. However, there was little evidence of breeding among prey species in this winter study. The occurrence of egg sacs in a few Oncaea spp. individuals at Stn $\mathrm{C}$ shows that breeding may occur to some extent during midwinter, although the intensity of this breeding was not studied. Franz (1988) reported breeding among small copepods during late winter in the Eastern Weddell Sea, and Nöthig \& Gowing (1991) suggested that small copepods may utilise large protozooplankton during that part of the year. SchnackSchiel \& Mizdalski (1994) reported that Microcalanus pygmaeus may reproduce and grow year-round or perhaps has a 2 yr life cycle in the eastern Weddell Sea. However, the importance of this winter breeding has to be further investigated throughout the winter period. A third factor that may affect predation impact on large copepods during winter is a change in diet towards smaller copepods.

\section{Parasites}

The occurrence of typhloscolecid polychaetes $<0.5 \mathrm{~mm}$ in this study and during summer (Øresland \& Pleijel 1991) suggests that Eukrohnia hamata can become infected throughout the year. The polychaete size range and the percentage of infected and headless $E$. hamata during winter were both similar to those found during summer, indicating little seasonal variation in infection rate. The large polychaete $(3.9 \mathrm{~mm})$ found on a Sagitta maxima shows that infections are not limited to $E$. hamata. There exists no information about the life history of this polychaete. Laboratory observations on the polychaete behaviour and infection time are needed in order to quantify the impact of this polychaete on chaetognath populations.

Chaetognaths are rarely found with cestodes (Nagasawa 1991) and chaetognaths have been considered as accidental hosts representing a cul-de-sac for the cestodes (Weinstein 1973). In sharp contrast to existing data, the high occurrence of cestodes in this study indi- cates that chaetognaths may function as important intermediate hosts for cestodes that ultimately infect Antarctic vertebrates. Zooplankton are central in most trophic pathways from phytoplankton to vertebrates in Antarctic food webs (see Clarke 1988, Hopkins et al. 1993). Nematodes and trematodes are the most common parasites of chaetognaths in general (see review by Nagasawa 1991). The total absence of these parasites in this material and the high occurrence of cestodes is therefore remarkable, and the nature of these phenomena deserves more attention in the future.

\section{Conclusions}

Eukrohnia hamata appears to have constant vertical size and stage distribution and breeding may occur at a continuous low rate throughout the year in Gerlache Strait. In Euchaeta antarctica intense egg production occurs at least during midwinter and mating occurs during both summer and winter. Monthly data throughout the year is needed in order to describe the breeding of these species.

Eukrohnia hamata and Euchaeta antarctica do not cease feeding during winter. The estimates of daily predation impact by E. hamata (admittedly speculative at this state) suggest that copepod prey populations can potentially be drastically reduced in numbers due to predation during the long Antarctic winter. Such a predation effect during winter is, of course, strengthened by other predators, e.g. E. antarctica and Euphausia superba, that feed on copepods during winter in this area (Huntley et al. 1994). A geographical and temporal variability in predation impact, reproduction among prey populations, and changes in diet towards smaller and more abundant copepods, are suggested as possibly important counter acting factors. Mortality among these predators has not been investigated in Gerlache Strait during winter.

The occurrence of small ectoparasitic polychaetes on chaetognaths also during winter indicates that infection occurs throughout the year. The total absence of nematodes and trematodes and the high occurrence of cestodes in Eukrohnia hamata is highly remarkable and it is suggested that E. hamata may be an important transport host for cestodes that infect Antarctic vertebrates.

Acknowledgements. I am very much indebted to $M$. Huntley for inviting me to join the RACER winter expedition 1992 to the Antarctic Peninsula. I thank M. Koie for identifying the cestodes and B. Mayrhofer for making the figures. I thank M. Huntley and T L. Hopkins for valuable comments on the manuscript. This work was financially supported by grant no. DPP-88-17779 from the NSF (U.S.) to M. Huntley and through NFR (Sweden). 


\section{LITERATURE CITED}

Alvarino, A. (1990). Chaetognatha. In: Adiyodi, K. G., Adiyodi R. G. (eds.) Reproductive biology of invertebrates, Vol. IV, Part B: Fertilization, development, and parental care. Oxford IBH Publishing Co., New Delhi, p. 255-282

Bros, W. E., Cowell B. C. (1987). A technique for optimizing sample size (replication). J. exp. mar. Biol. Ecol. 114: $63-71$

Clarke, A. (1988). Seasonality in the Antarctic marine environment. Comp. Biochem. Physiol. 90B: 461-473

Feigenbaum, D. K. (1982). Feeding by the chaetognath, Sagitta elegans, at low temperatures in Vineyard Sound, Massachusetts. Limnol. Oceanogr. 27: 699-706

Ferrari, F., Dojiri, M. (1987). The calanoid copepod Euchaeta antarctica from Southern Ocean Atlantic sector midwater trawls, with observations on spermatophore dimorphism. J. crust. Biol. 7: 458-480

Fransz, H. G. (1988). Vernal abundance, structure and development of epipelagic copepod populations of the eastern Weddell Sea (Antarctica). Polar Biol. 9: 107-114

Hagen, W. (1985). On distribution and population structure of Antarctic Chaetognatha. Meeresforsch. 30: 280-291

Hopkins, T. L., Lancraft, T. M., Torres, J. J., Donnelly, J. (1993). Community structure and trophic ecology of zooplankton in the Scotia Sea marginal ice zone in winter (1988). Deep Sea Res. I 40: 81-105

Huntley, M. E., Nordhausen, W., Lopez, M. D. G. (1994). Elemental composition, metabolic activity and growth of Antarctic krill Euphausia superba during winter. Mar. Ecol. Prog. Ser. 107: 23-40

Kott, P. (1953). Modified whirling apparatus for the subsampling of plankton. Austr. J. mar. Res. 4: 387-393

Lancraft, T. M., Hopkins, T L., Torres, J. J., Donnelly, J (1991). Oceanic micronektonic/macrozooplanktonic community structure and feeding under ice covered Antarctic waters during the winter (AMERIEZ 1988). Polar Biol. 11: $157-167$

Motoda, S. (1959). Devices of simple plankton apparatus. Mem. Fac. Fish. Hokkaido Univ. 7: 73-94

Nagasawa, S. (1991). Parasitism and diseases in chaetognaths. In: Bone, Q., Kapp, H., Pierrot-Bults, A. C. (eds.) The biology of chaetognaths. Oxford University Press, Oxford, p. 76-85

Nöthig, E.-M., Gowing, M. M. (1991). Late winter abundance and distribution of phaeodarian radiolarians, other large

This article was submitted to the editor protozooplankton and copepod nauplii in the Weddell Sea, Antarctica. Mar. Biol. 111: 473-484

Oresland, V. (1987). Feeding of the chaetognaths Sagitta elegans and $S$. setosa at different seasons in Gullmarsfjorden Sweden. Mar. Ecol. Prog. Ser. 39: 69-79

Øresland, V. (1990). Feeding and predation impact of the chaetognath Eukrohnia hamata in Gerlache Strait. Antarctic Peninsula. Mar. Ecol. Prog. Ser. 63: 201-209

Øresland, V. (1991). Feeding of the carnivorous copepod Euchaeta antarctica in Antarctic coastal and oceanic waters. Mar. Ecol. Prog. Ser. 78: 41-47

Øresland, V., Pleijel, F. (1991). An ectoparasitic typhloscolecid polychaete on the chaetognath Eukrohnia hamata from the Antarctic Peninsula. Mar. Biol. 108: 429-432

Øresland, V., Ward, P. (1993). Summer and winter diet of four carnivorous copepod species around South Georgia. Mar. Ecol. Prog. Ser. 98: 73-78

Pearre, S. Jr (1991). Growth and reproduction. In: Bone, $Q$. . Kapp, H., Pierrot-Bults, A. C. (eds.) The biology of chaetognaths. Oxford University Press, Oxford, p. 61-75

Prepas, E. E. (1984). Some statistical methods for the design of experiments and analysis of samples. In: Downing, J. A., Rigler, F. H. (eds.) A manual on methods for the assessment of secondary productivity in fresh waters, 2 nd edn. Blackwell Sci. Publ., Oxford, p. 266-335

Sands, N. J. (1980). Ecological studies on the deep-water community of Korsfjorden, western Norway. Population dynamics of the chaetognaths from 1971-1974. Sarsia 65: $1-12$

Schnack-Schiel, S. B., Mizdalski, E. (1994). Seasonal variations in distribution and population structure of Microcalanus pygmaeus and Ctenocalanus citer (Copepoda: Calanoida) in the eastern Weddell Sea. Mar. Biol. 119: $357-366$

Terazaki, M. (1991). Deep sea chaetognaths. In: Bone, Q., Kapp, H., Pierrot-Bults, A. C. (eds.) The biology of chaetognaths. Oxford University Press, Oxford, p. 117-121

Ward, P., Robins, D. B. (1987). The reproductive biology of Euchaeta antarctica Giesbrecht (Copepoda: Calanoida) at South Georgia. J. exp. mar. Biol. Ecol. 108: 127-145

Weinstein, M. (1973. Studies on the relationship between Sagitta elegans Verrill and its endoparasites in the southwestern Gulf of St. Lawrence. Ph.D. thesis, McGill University, Montreal

Yen, J. (1991). Predatory feeding behavior of an Antarctic marine copepod, Euchaeta antarctica. Polar Res. 10: 433-442

Manuscript first received: September 15, 1994

Revised version accepted: January 20, 1995 